\title{
Exploring Correlation between Highway Intersection Capacity and Traffic Parameters
}

\author{
Samra Sarwar ${ }^{1 *}$, Tibor Sipos¹, Muhammad Tabish Bilal¹, Bence Verebélyi \\ 1 Department of Transportation and Vehicle Engineering, Faculty of Transportation Engineering and Vehicle Engineering, \\ Budapest University of Technology and Economics, H-1111 Budapest, Stoczek utca 2, Hungary \\ 2 relativeGAP Ltd., Suite 1, 5th Floor, City Reach 5 Greenwich View Place, London E14 9NN, United Kingdom \\ * Corresponding author, e-mail: samrasarwar04@gmail.com
}

Received: 26 February 2020, Accepted: 26 March 2020, Published online: 18 September 2021

\begin{abstract}
The key role of this research is a comparison between traditional strategic transport modelling of intersections of a road network with the real-time observed and calculated data. The significance of this research is to evaluate the traditional strategic transport modelling on mesoscopic level, which able to study the network level impacts of smaller traffic engineering and traffic management interventions in a precise way. This research attempts to quantify the correlation between highway intersection capacity and traffic parameters, for this there is a need to determine the capacity values of different node types. This situation gives rise to a question that is dealt with in this research. "How different traffic parameters can be interrelated with the capacity of intersections by using different simulations?". This paper used assignment procedure, and usage of real-time data set with the calibration of Budapest Transport Model. Five contiguous intersections are selected on a small section of road network and traffic data was collected on them. The intersections are simulated by the assignment of intersection capacity analysis (ICA) method. During analysis of traffic parameters, the actual values of saturation flow rate are quite different from the base model value, which results in different capacities of all nodes. Comparisons have been made between the travel times at zones, links, and nodes' levels while each comparison demonstrates a huge difference in actual traffic survey data model and base model. It has been concluded from the analysis that Budapest base transport model is very far from reality.
\end{abstract}

Keywords

intersection capacity analysis, Budapest Transport Model, PrT assignment, passenger cars

\section{Introduction}

Most of the macroscopic traffic simulation models and highway capacity approaches were studied for the highway networks only in literature. An important consideration of the capacity of a highway network is that it is mostly driven by intersection impedance. There are different capacity estimation techniques that depend on data requirements, modelling effort, different parameter values and statistical differences across time and over geographically dispersed locations. This paper attempts to quantify the correlation between highway intersection capacity and traffic parameters. In order to do this analysis, there is a need to determine the capacity values of different node types. For capacity values, a macro-level transport model is presented for which, PTV Visum is a versatile tool that is used for the detailed analysis of intersections, such as relevant coefficients which are significant for dimensioning the road cross-sections and intersection types. In order to gain a more detailed relationship between specific conditions in which traffic flow operates and the consequential relationship between basic traffic flow characteristics, the intersection could be characterized as a node with traffic lines incoming to and outgoing from this point by only changing boundary conditions. For the purpose of determining the intersection capacity, it is necessary to conduct research of relevant traffic parameters on the observed intersections. For the analysis of relevant traffic parameters such as speed, volume, flow, and headway; survey data for travel behavior analysis, annual traffic volume data, and Budapest Transport Model (EFM) database for data analyzing processes will be required. Operative model of EFM Model in PTV Visum format is used to observe and calculate the traffic condition on the observed intersection.

Capacity is usually the maximum hourly passage of vehicles through the road network and intersection. Many 
highway capacity approaches and simulations define the capacity of a network, albeit the traffic intersections are problem spots on a highway network.

The goal of this research is to develop a method that can be used to determine the capacity of intersection by node impedance calculation technique. Travel times for private transport vehicles are determined by the saturation flow of links, turning movements and bottleneck effect at intersections which results from the traffic volume and capacity of these network objects. The major objectives are:

- to calculate and analyze the performance of intersections along with a network of an existing assignment result with comprehensive models. To calculate the aspects of nodes, which are responsible for high impedance various parameters are required i.e. saturation flow, intersection geometry, green time, and driver behavior;

- to execute a procedure that correlates the traffic flow parameters with traffic volume and capacity of network intersections;

- comparison of model results with Budapest Transport Model (EFM);

- to execute a model that can be further used to generate complete city models.

\section{Literature review}

HCM defined the capacity of a facility as "the maximum sustainable hourly flow rate at which persons or vehicles reasonably can be expected to traverse a point or a uniform section of a lane or roadway during a given time period under prevailing roadway, environmental, traffic, and control conditions" (National Research Council (U.S.). Transportation Research Board, 2010). The conventional theory supports that saturation flow is the steady maximum queue discharge rate of traffic across the stop-line and the discharge rate reaches maximum value after a short time from the green onset and then maintains constant during the green time until the queue is completely dissolved (Tang and Nakamura, 2008). In order to determine the saturation flow rate the base conditions of a signalized intersection have to determine first. Base conditions for signalized intersections are defined for the through lane group while, turn radius also has a great effect on the capacity of those lanes which have a turn radius less than 45 meters in real life situation (Shao et al., 2011). Increase in the traffic intensity leads to a situation when it is difficult to provide a satisfactory level of service with traffic light signaling systems. With a traffic signal if there is congestion at a section of the road traffic network it leads to the situation when the average duration of the vehicle delay exceeds the length of the traffic signaling cycle. In this case, the queue length can increase, reaching the length of the road intersection (Szabó and Török, 2019). If there is the further development of the road blocking it paralyzes larger parts of the road network and disorganizes the traffic in whole network (Chubukov et al., 2017).

\subsection{Methods for estimating the capacity of road network intersections}

At intersections, the capacity is defined for each lane on each approach. Capacity of group lanes is the maximum hourly rate at which vehicles can practically pass through the intersection under specific prevailing traffic conditions, roadway conditions, and signal conditions. Traffic conditions include distribution of vehicles, vehicle type, and volume on each approach. Roadway condition includes the intersection infrastructure and intersection geometry. Signalized intersection conditions include signal phasing, timing, and type of control of the signal (National Research Council (U.S.). Transportation Research Board, 2010). The intersection capacity is the capacities of approaches to the intersection, which depends on the green time allocated to each approach, the cycle length of the intersection, the saturation flow rate of the approach, and the characteristics of the approaching flows. The capacity of an approach of the intersection can be determined as (Tian, 2002):

$$
\mathrm{c}_{\mathrm{a}}=\mathrm{s}_{\mathrm{a}} \cdot\left[\frac{\mathrm{G}}{\mathrm{C}}\right]_{\mathrm{a}}
$$

where, $c_{a}$ denotes the capacity to approach $a$, in vehicles per hour (vph); $\mathrm{s}_{\mathrm{a}}$ denotes the saturation flow rate for approach a, in vph; $\mathrm{C}$ denotes the cycle length of the intersection, in seconds; and $\mathrm{G}_{\mathrm{a}}$ denotes effective green time for approach a, in seconds.

Capacity is limited not only by physical space but also by the time available for the movements (National Research Council (U.S.). Transportation Research Board, 2010). Daganzo discussed an actuated control strategy in which actuated systems end the green phase on each approach as soon as its queue dissipates (Daganzo and Geroliminis, 2008). This strategy operates with cycles and phases close to the minimum while avoiding overflows. Daganzo and Geroliminis (2008) derived the cycle length equation for this actuated control strategy, which can be determined as:

$$
\overline{\mathrm{c}}=\frac{\mathrm{L}}{1-\Sigma_{\mathrm{i}} \mathrm{y}_{\mathrm{i}}},
$$


where, $\mathrm{y}_{\mathrm{i}}$ denotes the effective green time ratio; $\mathrm{L}$ denotes the lost time in each cycle.

\subsection{Traffic flow parameters}

HCM 2000 used three basic parameters to describe the traffic on any highway which are volume or flow rate, speed, and density while mostly the macroscopic and microscopic traffic simulation models and highway design approaches have historically analyzed freeways in terms of traffic flow parameters, such as speed, volume, and density (National Research Council (U.S.). Transportation Research Board, 2010). The use of lane-by-lane analysis reflects that most traffic flow parameters do not have uniform volumes across all available lanes on the road network, and such non-uniformity may be of considerable traffic engineering consequence (Carter et al., 1999). The average travel time and speed is related to the number of commuters, which is further split into the bus and car passengers (Smeed, 1968).

\section{Methodology}

The methodology adopted for executing this research is presented in a flowchart format Fig. 1. External data sources used to collect the data regarding different parameters of intersections, databases of Budapest transport EFM model on PTV Visum and traffic signal data of Budapest road network were collected from Budapesti Közlekedési Központ (BKK) organization.

\subsection{Model calibration}

Good quality of counts is required for calibration (Szabó et al., 2019). Traffic counts are obtained from Manual classified counts which are significantly accurate for the calibration of assigned traffic flows in the base scenario. Calibration of assigned traffic flows in the base scenario was generally restricted to cars and all other vehicles. Manual classified counts are used to determine the proportion of cars. Turning movement counts are more accurate for precise calibration which have been used to update the assigned traffic flows and used for the model calibration. During calibration the core purpose of matrix estimation is the adjustment of existing model based on traffic counts of surveys and to improve estimation of movements in the existing model. Calibration function in running the procedure sequence in PTV Visum is the function that uses count data to estimate the predicted factors based on assignment results of the model for sum of private transport demand matrix.

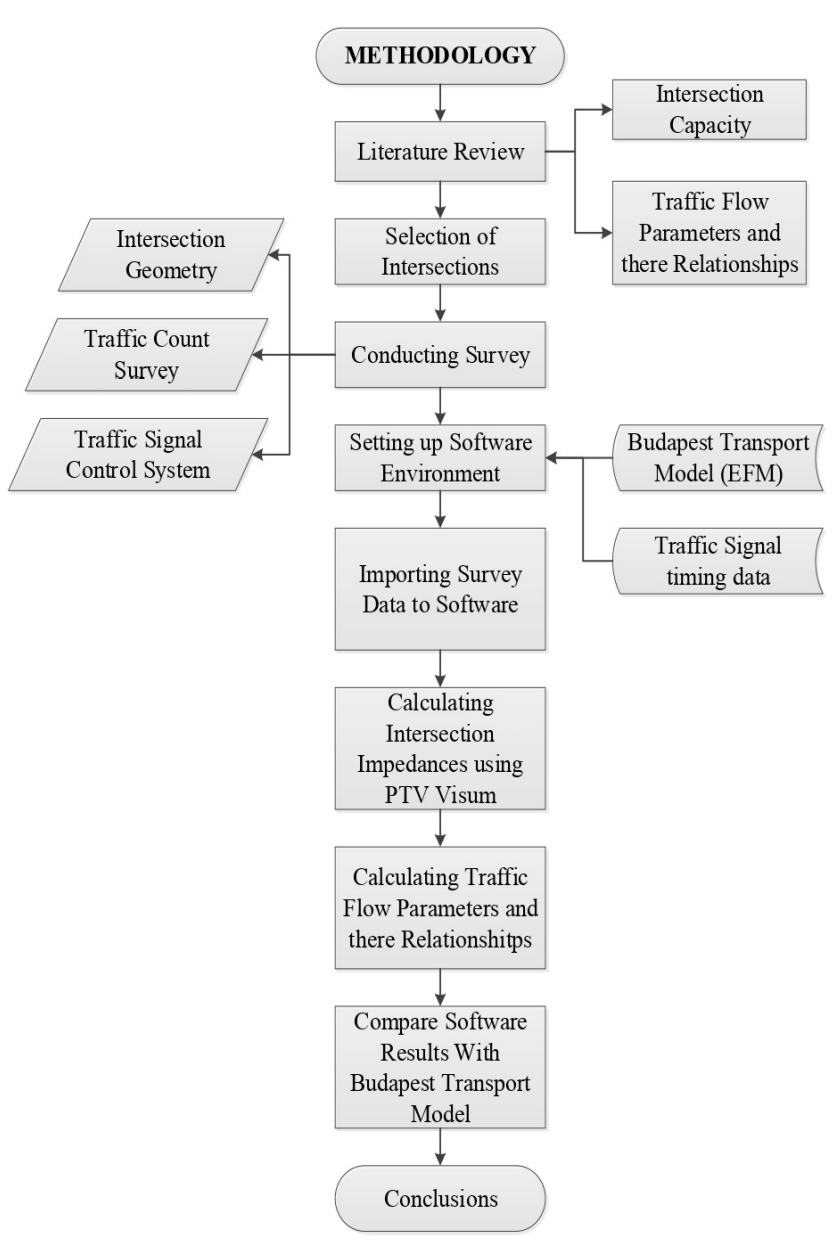

Fig. 1 Flowchart of methodology

\subsection{Modelled area}

The study area was chosen near the city center of Budapest city. According to Hungarian central statistical data, the city of Budapest covers a surface area of 525.2 square kilometers. With a population near 1.77 million, and population density is approximately 3,351 people living per square kilometer. The Budapest transport model is based on the road network of about 30,000 links with 10,700 nodes distributed in 1201 different zones. Five signalized intersections were selected. These chosen signalized intersections with names: Moricz Zsigmond Korter, Lagymanyosi ut - Menesi ut, Gardonyi ter, Csiky ut - Orlay ut, and Szent Gellert ter Muegyetem are shown in Fig. 2. These are successive intersections on one route network with length $0.85 \mathrm{~km}$ which is shown in Fig. 3. The spacing of the successive intersections has critical importance, as less distance between the intersections influences the efficient functioning of the intersections.

\subsection{Data collection}

Data collection is obligatory in order to make a transport model and related parameters used in that model. Traffic 


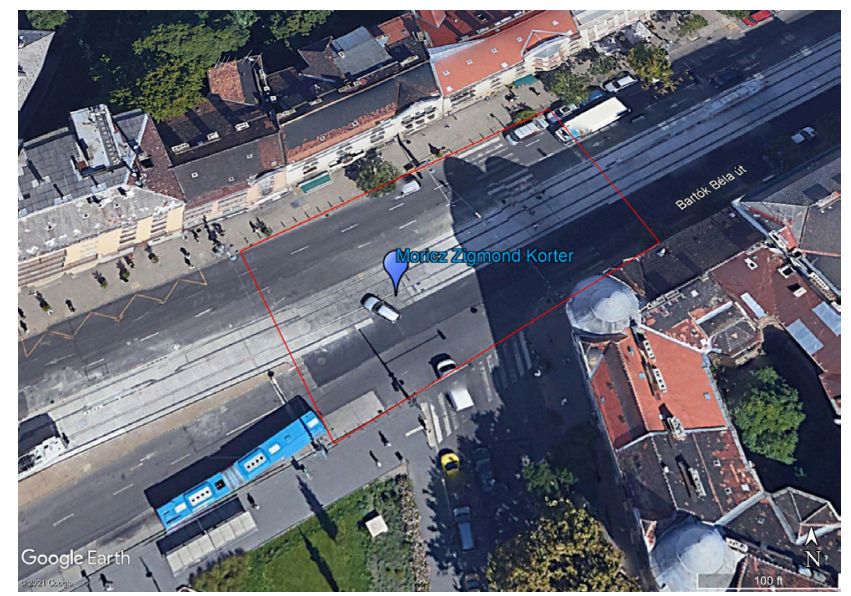

a)

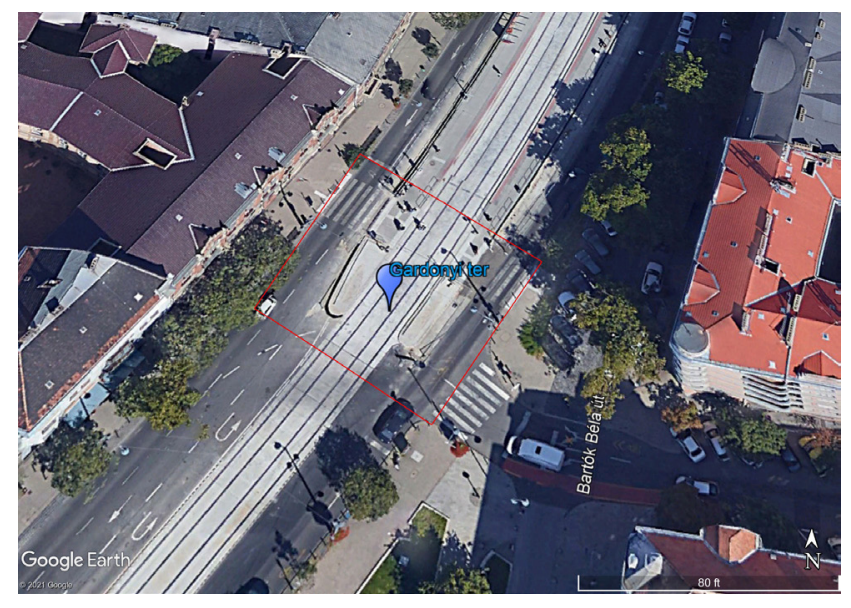

c)

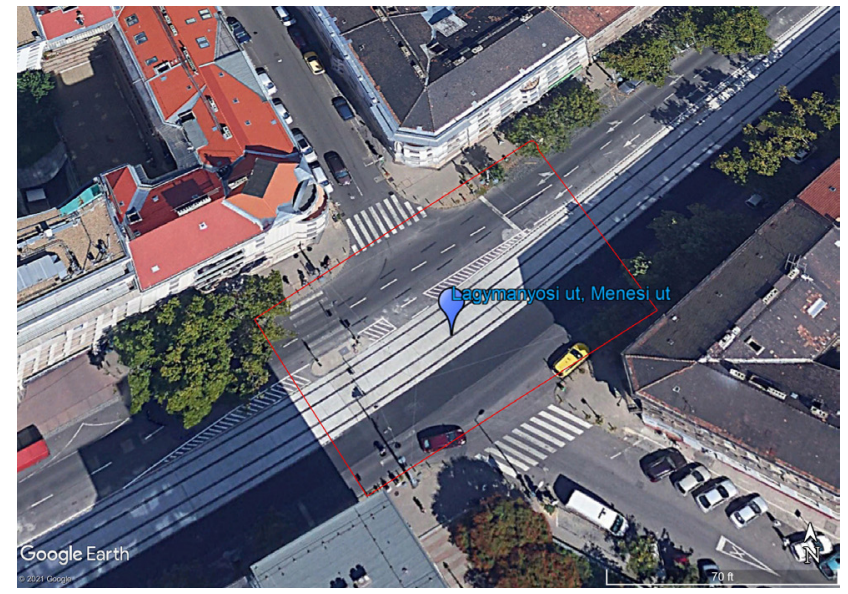

b)

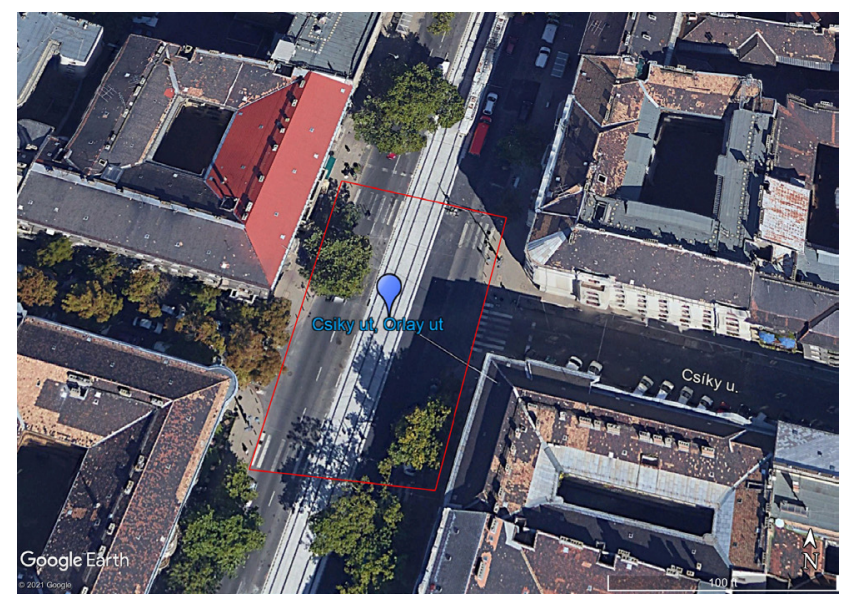

d)

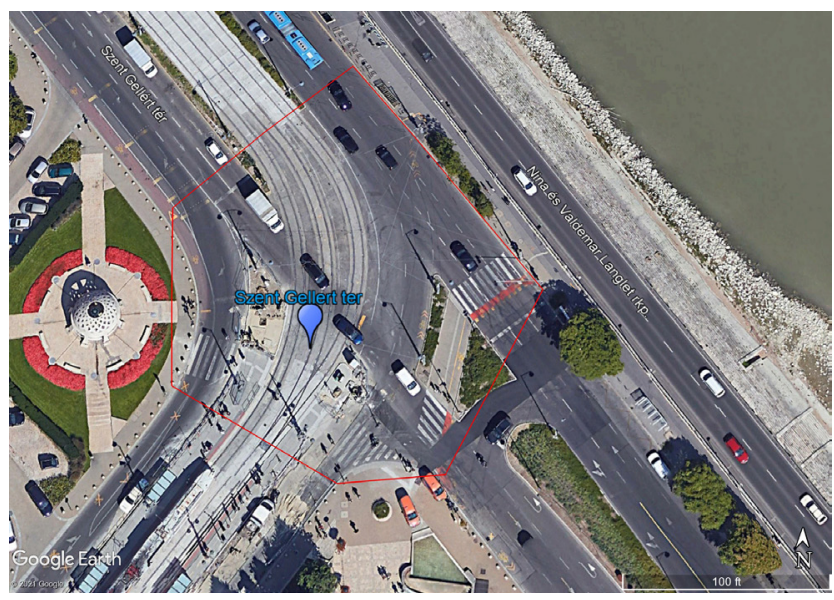

e)

Fig. 2 Layout of Selected Intersection a) Moricz Zsigmond Korter; b) Lagymanyosi ut - Menesi ut; c) Gardonyi ter; d) Csiky ut - Orlay ut; e) Szent Gellert ter Muegyetem

data was collected at all selected signalized intersections. The data collected encompasses various parameters like traffic volume of all turning movements, traffic composition, and signal timing at different approaches. In this regard, a rational survey process was used. Random sampling technique is used for the selection of intersections. Traffic data was collected at all signalized intersections by Videography method. Morning peak period turning 


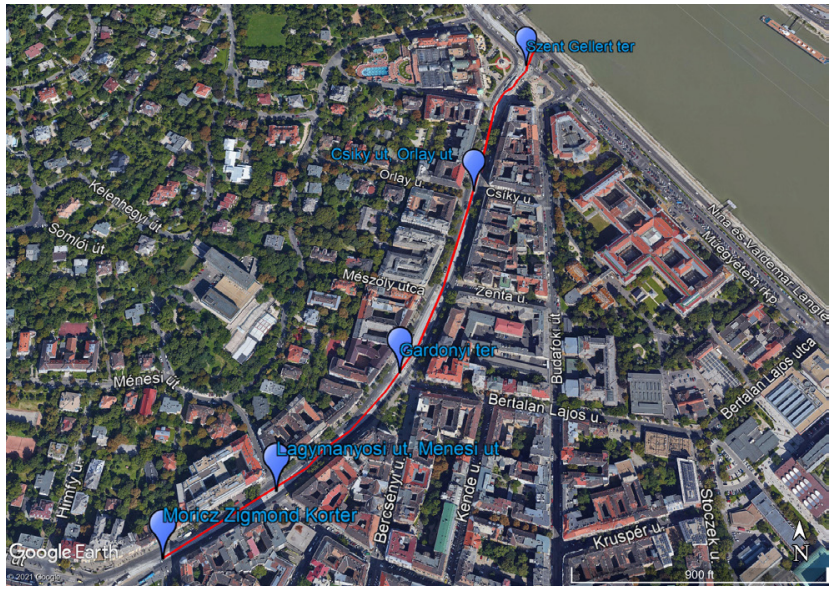

Fig. 3 Selected area for modelling

movement data was collected to support the traffic analysis. The following parameters were collected and calculated from traffic survey data:

- the geometry of intersection;

- number of approaching legs and their order in each intersection;

- number of traffic lanes and width on every approach of the intersection;

- types of turns on each leg included prohibited turns (each turning movements on each leg;

- intersection control type (two-way stop, two-way yield, signalized, roundabout, uncontrolled);

- signal times and signal phases;

- saturation flows on each lane and leg of the intersection.

\section{Intersection analysis}

Data analysis of various traffic characteristics such as traffic volume, traffic composition, and peak hour traffic volume, etc. were done for each turning movement, each approach, and nodes of all selected intersections. Intersection maneuvers were assessed by using the PTV Visum software package (Version 18.0), using 2010 HCM standards (National Research Council (U.S.). Transportation Research Boardl, 2010). Actual road network geometry and traffic control system were used for the intersection analysis. Intersections are analyzed by the assignment of ICA method in PTV Visum, Fig. 4 describes the flow hierarchy of the overview of ICA method outcomes.

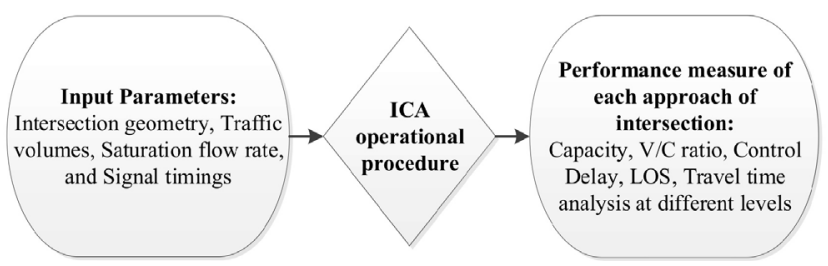

Fig. 4 Overview of ICA operational procedure
Two important requirements can be evaluated by using ICA intersection analysis:

- Accurate impedance modelling of the nodes in detail using intersection capacity analysis (ICA).

- The impedances and capacities evaluated by the means of ICA are not directly used to replace volume-delay (VD) function. As this method overcomes the problem of non-separable function computing them by approximation.

This method consists of interaction between equilibrium assignment method which also includes VD function and node impedance calculation method.

\subsection{Quality of calibrated data}

Before the analysis, traffic counts survey data is calibrated by assuming the confidence intervals. Good quality of traffic count survey data is essential for calibration. Calibration function in running the procedure sequence in PTV Visum is the function which balances the matrices of traffic counts survey data. Table 1 shows the values of traffic counts survey data and calibrated data. To check the accuracy of the generated calibrated data, Wilcoxon Signed Rank is executed, from which $\mathrm{z}$ value is calculated which is -0.4 and by considering $5 \%$ significance level corresponding $\mathrm{z}_{\text {critical }}$ value is 1.96 . By assuming null hypothesis $z$ value should be between -1.96 and 1.96 , the resultant value is -0.4 which is between the range. Hence, there is strong evidence that calibrated data is not significantly different from traffic counts surveyed data. So, it depicts the real picture of surveyed data.

\subsection{Interrupted flow parameters}

As the selected intersections are the signalized, therefore, the following parameters are assessed:

- saturation flow rate and time headways;

- capacity of intersections;

- delays and level of service.

Table 1 Total traffic volume at each intersection

\begin{tabular}{lcc}
\hline Intersection name & $\begin{array}{c}\text { Traffic volume } \\
\text { surveyed data }\end{array}$ & $\begin{array}{c}\text { Calibrated model } \\
\text { traffic volume }\end{array}$ \\
\hline Moricz Zsigmond Korter & 1572 & 1686 \\
Lagymanyosi ut - Menesi ut & 1998 & 1821 \\
Gardonyi ter & 1650 & 1435 \\
Csiky ut - Orlay ut & 1128 & 1307 \\
Szent Gellert ter Muegyetem & 3114 & 2937 \\
\hline
\end{tabular}


The geometry of an intersection affects the traffic volume of that intersection, while the saturation flow rate influences the supply of an intersection. The survey traffic count data was collected for every turning movement from which saturation time headway is calculated for 10 cycles of traffic signals for each turning movement of each approach of intersections, which proceeds in the calculation saturation flow rate by using intersection capacity analysis (ICA) method in PTV Visum, by using HCM 2010, Eq. (3) (National Research Council (U.S.) Transportation Research Board, 2010):

$$
\begin{aligned}
& \mathrm{s}_{\mathrm{i}}=\left(\mathrm{s}_{\mathrm{o}}\right)(\mathrm{N}) *\left(\mathrm{f}_{\mathrm{w}}\right)\left(\mathrm{f}_{\mathrm{HV}}\right)\left(\mathrm{f}_{\mathrm{g}}\right)\left(\mathrm{f}_{\mathrm{p}}\right)\left(\mathrm{f}_{\mathrm{a}}\right)\left(\mathrm{f}_{\mathrm{bb}}\right) \\
& \left(\mathrm{f}_{\mathrm{Lu}}\right)\left(\mathrm{f}_{\mathrm{RT}}\right)\left(\mathrm{f}_{\mathrm{LT}}\right)\left(\mathrm{f}_{\mathrm{Lpb}}\right)\left(\mathrm{f}_{\mathrm{Rpb}}\right)\left(\mathrm{f}_{\mathrm{wZ}}\right)\left(\mathrm{f}_{\mathrm{ms}}\right)\left(\mathrm{f}_{\mathrm{sp}}\right),
\end{aligned}
$$

where, $s_{i}$ is saturation flow rate of lane group $i$, so is ideal saturation flow rate per lane (generally 1,900 vehicles per hour per lane (vphpl)), $\mathrm{N}$ is Number of lanes in lane group, $\mathrm{fw}$ is factor for lane width adjustment, $\mathrm{f}_{\mathrm{HV}}$ is HGV adjustment factor, $f_{g}$ is adjustment factor for approach grade, $f_{p}$ is adjustment factor for parking, $f_{a}$ is adjustment factor for the position of the link to city center, $\mathrm{f}_{\mathrm{bb}}$ is adjustment factor for bus stop blocking, fLu is adjustment factor for lane usage, fRT is adjustment factor for right turns, $f_{L T}$ is adjustment factor for left turns, $f_{\text {Lpb }}$ is adjustment factor for pedestrians and bicyclists on left turns, $\mathrm{f}_{\mathrm{Rpb}}$ is adjustment factor for pedestrians and bicyclists on right turns, $\mathrm{f}_{\mathrm{wZ}}$ is adjustment factor for work zones, $\mathrm{f}_{\mathrm{ms}}$ is adjustment factor for lane blocking, and $\mathrm{f}_{\mathrm{sp}}$ is adjustment factor for persistent spillback these all values are automatically calculated in ICA method.

Table 2 shows the saturation flow rate for all approaches of all selected intersections. EFM model has been designed on HCM 2010 standards, where the saturation flow rate value is $2000 \mathrm{veh} / \mathrm{hr}$, while from the results as shown in Table 2 it is clearly obvious that saturation flow rate of real-time data is significantly variating from the standard values of HCM 2010 (National Research Council (U.S.). Transportation Research Board, 2010).

For signalized intersections, capacity not only depends on the saturation flow rate, but many other parameters affect it. Capacity accounts for road conditions such as number and width of lanes, signal timings of lanes, and lane use allocations. The capacity has been calculated by using Eq. (4) from HCM 2010 during ICA procedure sequence (National Research Council (U.S.) Transportation Research Board, 2010):

\begin{tabular}{|c|c|c|c|c|}
\hline $\begin{array}{l}\text { Road } \\
\text { name }\end{array}$ & $\begin{array}{c}\text { Intersection } \\
\text { name }\end{array}$ & $\begin{array}{l}\text { Approach } \\
\text { name }\end{array}$ & $\begin{array}{l}\text { Average } \\
\text { Saturation } \\
\text { flow rate } \\
\text { per lane } \\
(\mathrm{Veh} / \mathrm{hr} / \mathrm{L})\end{array}$ & $\begin{array}{c}\text { Volume/ } \\
\text { Capacity } \\
\text { at each } \\
\text { approach } \\
\left(\mathrm{X}_{\mathrm{c}}=\mathrm{V} / \mathrm{C}\right)\end{array}$ \\
\hline \multirow{16}{*}{$\begin{array}{l}\text { Bartok } \\
\text { Bela ut }\end{array}$} & \multirow{3}{*}{$\begin{array}{l}\text { Moricz } \\
\text { Zsigmond } \\
\text { Korter }\end{array}$} & Eastbound & 1671 & 0.40 \\
\hline & & Westbound & 1445 & 0.53 \\
\hline & & Northbound & 1395 & 0.74 \\
\hline & \multirow{3}{*}{$\begin{array}{l}\text { Lagymanyosi } \\
\text { ut - Menesi ut }\end{array}$} & Eastbound & 1900 & 0.45 \\
\hline & & Westbound & 1620 & 0.40 \\
\hline & & Southbound & 1350 & 0.30 \\
\hline & \multirow{3}{*}{ Gardonyi ter } & Northbound & 1267 & 0.90 \\
\hline & & Southbound & 1519 & 0.50 \\
\hline & & Westbound & 1440 & 0.58 \\
\hline & \multirow{3}{*}{$\begin{array}{l}\text { Csiky ut - } \\
\text { Orlay ut }\end{array}$} & Northbound & 1486 & 1.00 \\
\hline & & Southbound & 1231 & 0.90 \\
\hline & & Westbound & 2000 & 0.41 \\
\hline & \multirow{4}{*}{$\begin{array}{c}\text { Szent } \\
\text { Gellert ter } \\
\text { Muegyetem }\end{array}$} & Eastbound & 1908 & 0.60 \\
\hline & & Southbound & 1585 & 0.98 \\
\hline & & $\begin{array}{l}\text { Right-turn } \\
\quad \mathrm{W} \rightarrow \mathrm{S}\end{array}$ & 1270 & 0.87 \\
\hline & & Northbound & 1433 & 0.98 \\
\hline
\end{tabular}

Table 2 Saturation flow rate and $\mathrm{V} / \mathrm{C}$ ratio on all intersection approaches

$\mathrm{c}_{\mathrm{i}}=\mathrm{s}_{\mathrm{i}} \cdot\left[\frac{\mathrm{g}_{\mathrm{i}}}{\mathrm{C}}\right]$,

where, $\mathrm{c}_{\mathrm{i}}$ denotes the capacity to approach $\mathrm{a}$, in $\mathrm{vph} ; \mathrm{s}_{\mathrm{i}}$ denotes the saturation flow rate for approach $\mathrm{a}$, in vph; $\mathrm{C}$ denotes the cycle length of the intersection, in seconds; and $\mathrm{g}_{\mathrm{i}}$ denotes effective green time for approach a, in seconds.

The critical volume to capacity (V/C) ratio of selected intersections have been calculated by the assignment of intersection capacity analysis (ICA) method in PTV Visum, which is based on the number of lanes, and various adjusted factors such as signal timings, saturation flow rate, and lane width by the application of Eq. (5):

$\mathrm{X}_{\mathrm{C}}=\Sigma_{\mathrm{i}}\left[\frac{\mathrm{v}}{\mathrm{s}}\right]_{c i} \frac{\mathrm{C}}{(\mathrm{C}-\mathrm{L})}$, 
where, $X_{c}$ is critical saturation (v/c ratio) per intersection, $[\mathrm{v} / \mathrm{s}]_{\mathrm{ci}}$ is volume/capacity ratios for all critical lane groups $\mathrm{C}$ is cycle time, and $\mathrm{L}$ is loss time total of the signal groups of all critical lane groups.

The $\mathrm{V} / \mathrm{C}$ ratio values in Table 2 are referred as the degree of saturation, as discussed in Federal Highway Administration Research and Technology (US Department of Transportation Federal Highway Administration, 2004), that if the value of $\mathrm{V} / \mathrm{C}$ ratio is less than 0.85 , it refers that the satisfactory capacity is available at given lane or approach of the intersection. Calculated $\mathrm{V} / \mathrm{C}$ ratio in Table 2 shows that the capacity at most of the approaches of the selected intersections is satisfactory because the $\mathrm{V} / \mathrm{C}$ value is less than 0.85 . But at some approaches the value is between 0.85 and 1 , it seems that the traffic volume somehow equals the capacity and delays may occur. But the data was recorded in morning peak hours then the values between 0.85 and 0.95 are satisfactory because intersections are designed between 0.85 to 0.95 values during peak hours.

In interrupted flow, the performance of the intersections can also be assessed by the delay time at that intersection. Many factors influence the delay time values i.e., slow vehicle movements, stops on intersection approaches, driver behaviour, total traffic volume, cycle time, and effective green time. For the calculation of mean turn time at nodes, node impedance calculation method has been used in PTV Visum which is ICA assignment method by considering many parameters i.e., uniform delay, delay calibration, initial queue delay, progression faction, and proportion arriving on the green.

Mean total delay on each lane has been calculated by HCM 2010 method for each lane by using Eq. (6) (National Research Council (U.S.) Transportation Research Board, 2010). Such delay depends on uniform delay, incremental delay, and delay residual demand:

$\mathrm{d}_{\mathrm{i}}=\mathrm{d}_{\mathrm{Ui}} \mathrm{PF}+\mathrm{d}_{\mathrm{Ii}}+\mathrm{d}_{\mathrm{Ri}}$,

where $\mathrm{PF}$ is the progression factor, and all other variables has been discussed below.

According to HCM 2010 the uniform delay is that delay which is expected in the uniform distribution arrivals which has been calculated by considering Eq. (7) (National Research Council (U.S.) Transportation Research Board, 2010):

$$
\mathrm{d}_{\mathrm{ui}}=0.5 * \mathrm{c} * \frac{\left(1-\frac{\mathrm{g}_{\mathrm{i}}}{\mathrm{c}}\right)^{2}}{1-\left(\frac{\mathrm{g}_{\mathrm{i}}}{\mathrm{c}}\right) \cdot\left(\min \left(\mathrm{X}_{\mathrm{i}}, 1\right)\right)},
$$

where, $d_{u i}$ is the uniform delay for lane group $i, g_{i}$ is the effective green time, and $\mathrm{X}_{\mathrm{i}}$ is volume by capacity ratio.

The incremental delay for each lane of the intersection is that delay which occurs when arrivals are not uniformly distributed and some cycles are overflow, then according to HCM 2010 it has been calculated in ICA analysis method by considering Eq. (8) (National Research Council (U.S.). Transportation Research Board, 2010):

$\mathrm{d}_{\mathrm{Ii}}=900 \cdot \mathrm{T} \cdot\left(\mathrm{X}_{\mathrm{i}}-1\right)+\sqrt{\left(\mathrm{X}_{\mathrm{i}}-1\right)^{2}+\frac{8 \cdot \mathrm{k}_{\mathrm{i}} \cdot \mathrm{I}_{\mathrm{i}} \cdot \mathrm{X}_{\mathrm{i}}}{\mathrm{c}_{\mathrm{i}} \cdot \mathrm{T}}}$,

where, $\mathrm{d}_{\mathrm{Ii}}$ is incremental delay for lane group $\mathrm{i}, \mathrm{c}_{\mathrm{i}}$ is the capacity for lane group $\mathrm{i}, \mathrm{X}_{\mathrm{i}}$ is the volume to capacity ratio, $\mathrm{T}$ is duration of analysis period, and $\mathrm{I}$ is the upstream filtering.

According to HCM 2010 residual demand is the unmet demand at the beginning of analysis period, evaluated by using following HCM 2010 Eq. (9) (National Research Council (U.S.) Transportation Research Board, 2010):

$\mathrm{d}_{\mathrm{Ri}}=\frac{1800 \cdot \mathrm{Q}_{\mathrm{bi}} \cdot\left(1+\mathrm{u}_{\mathrm{i}}\right) \cdot \mathrm{t}_{\mathrm{i}}}{\mathrm{C}_{\mathrm{i}} \cdot \mathrm{T}}$,

where, $Q_{b} i$ is initial unmet demand (default value 0 ), $u_{i}$ is delay parameter, and $t_{i}$ is duration of unmet demand in time $\mathrm{T}$.

Total delay at each approach has been calculated by weighted delay at each approach by using HCM 2010 Eq. (10) (National Research Council (U.S.) Transportation Research Board, 2010):

$\mathrm{d}_{\mathrm{A}}=\frac{\sum \mathrm{d}_{\mathrm{i}} \cdot \mathrm{V}_{\mathrm{i}}}{\sum \mathrm{V}_{\mathrm{i}}}$,

where $d_{A}$ is the mean delay of each lane, $d_{i}$ is delay for lane group $i$, and $V_{i}$ is volume of lane group $i$.

The intersection delay has been assessed by using HCM 2010 Eq. (11) (National Research Council (U.S.) Transportation Research Board, 2010):

$\mathrm{d}_{\mathrm{I}}=\frac{\sum \mathrm{d}_{\mathrm{A}} \cdot \mathrm{V}_{\mathrm{A}}}{\sum \mathrm{V}_{\mathrm{A}}}$,

where $V_{A}$ is volume of approach.

In order to get clear picture of mean delay values Fig. 5 reveals the average turn time (time for straight movements also) for one vehicle at each intersection. From the mean delay value for each node, corresponding level of service (LOS) is assessed by using HCM 2010 standard threshold values for LOS which are given Table 3. From the given Table 3 Csiky ut - Orlay ut and Szent Gellert ter Muegyetem have "D" LOS which is due to traffic jam 


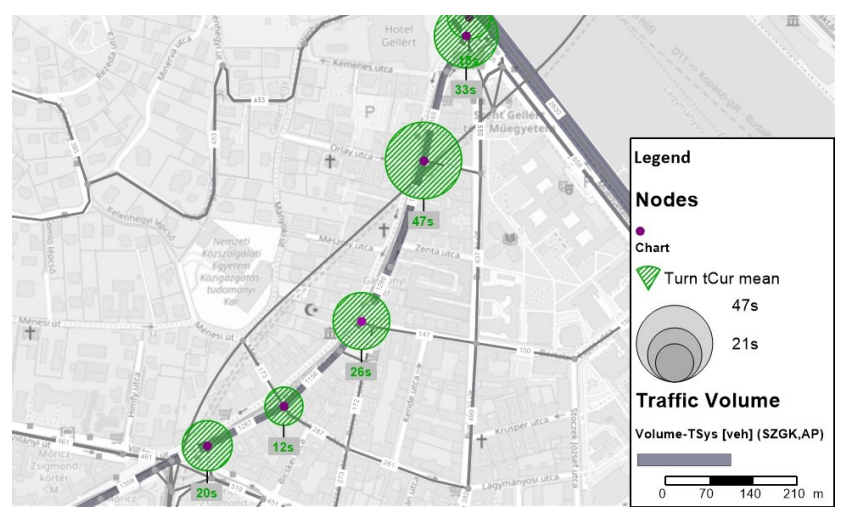

Fig. 5 Mean turns time at nodes

Table 3 Level of service at nodes

\begin{tabular}{|c|c|c|c|}
\hline $\begin{array}{l}\text { Intersection } \\
\text { name }\end{array}$ & Approach name & $\begin{array}{c}\text { Delay at each } \\
\text { approach }\end{array}$ & $\begin{array}{l}\text { LOS at each } \\
\text { intersection }\end{array}$ \\
\hline \multirow{3}{*}{$\begin{array}{l}\text { Moricz } \\
\text { Zsigmond } \\
\text { Korter }\end{array}$} & Eastbound & B & \multirow{3}{*}{$\mathrm{C}$} \\
\hline & Westbound & $\mathrm{B}$ & \\
\hline & Northbound & $\mathrm{D}$ & \\
\hline \multirow{3}{*}{$\begin{array}{l}\text { Lagymanyosi } \\
\text { ut, Menesi ut }\end{array}$} & Eastbound & B & \multirow{3}{*}{ B } \\
\hline & Westbound & A & \\
\hline & Southbound & $\mathrm{C}$ & \\
\hline \multirow{3}{*}{ Gardonyi ter } & Northbound & $\mathrm{C}$ & \multirow{3}{*}{$\mathrm{C}$} \\
\hline & Southbound & $\mathrm{C}$ & \\
\hline & Westbound & $\mathrm{D}$ & \\
\hline \multirow{3}{*}{$\begin{array}{l}\text { Csiky ut - Orlay } \\
\text { ut }\end{array}$} & Northbound & $\mathrm{D}$ & \multirow{3}{*}{$\mathrm{D}$} \\
\hline & Southbound & $\mathrm{D}$ & \\
\hline & Westbound & $\mathrm{C}$ & \\
\hline \multirow{4}{*}{$\begin{array}{l}\text { Szent Gellert ter } \\
\text { Muegyetem }\end{array}$} & Eastbound & $\mathrm{B}$ & \multirow{4}{*}{$\mathrm{D}$} \\
\hline & Southbound & $\mathrm{E}$ & \\
\hline & Right-turn WS & $\mathrm{C}$ & \\
\hline & Northbound & $\mathrm{C}$ & \\
\hline
\end{tabular}

conditions for some time during survey at only 1 lane in southbound and northbound direction respectively.

\section{Comparison}

The traffic volume recorded in the EFM Model was daily traffic volume, but the data is collected only for the morning peak hours, therefore traffic volume in the model first changed to morning peak hour volumes, by multiplying the 0.07 factor which is a rounded number based on daily traffic profiles of automatic traffic counts (ATC) data in city centre areas in Budapest to the car, LGV, and HGV daily traffic matrices in base version. After the modification of the EFM model by generating real-time data in it, various analyses were done to assess the accuracy of the EFM model by implementing PrT assignment method considering assignment with ICA on actual data compare with the base version (without any interventions). From the PrT assignment travel times are assessed at various levels such as link, node, turn, and zones level.

\subsection{Travel time analysis at link level}

The actual travel time on links between selected intersections depends on actual velocity and real-time traffic volume. While base travel time depicts the EFM Model values. The actual and base travel times on links between selected intersections are calculated in Fig. 6, which reveals that there is a huge difference between travel time values. These differences are because of the different traffic volumes in base data on links from real-time data. It means that there is an unbalanced assignment of traffic volumes on links in the base version of the EFM Model.

\subsection{Travel time analysis at zone level}

The total travel time of all passenger cars based on the origin-destination (OD) pairs between zones which are determined by considering the route network, then the relative difference is calculated between actual and base total travel time in Fig. 7. From results in Fig. 7, it can be seen that there is an effective increase in the total travel time. There is a significant difference in total travel times of actual and base scenarios. The travel time analysis at the zone level reveals that travel demand is effectively different in

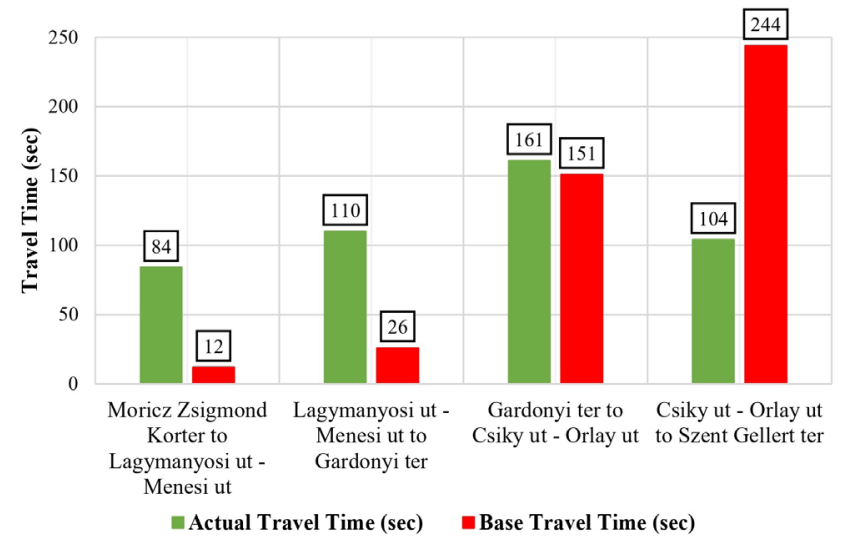

Fig. 6 Travel time comparison on links between selected intersections

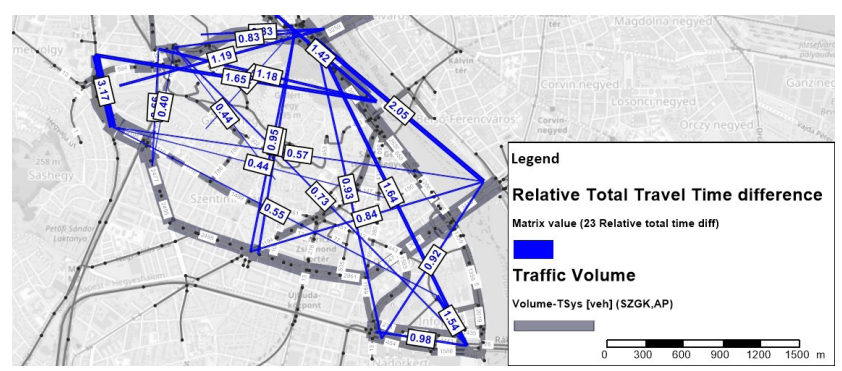

Fig. 7 Relative total travel time difference between zones 
EFM Model. The traffic volume values on which Budapest Transport Model is established are just expected values.

\subsection{Turn time analysis at node level}

Turns basically have the same correlation between travel time and capacity as the links, the only difference is that the turns have no actual length in PTV Visum. Turn travel time depends upon the free flow turn time, traffic volume at turns, capacity of turns, and the impedance at nodes. As we know the intersections are the bottlenecks of a transport network. The impedance at turns is directly correlated to the turn travel time. Turns travel time is calculated by ICA method, therefore the impedance calculation precisely considers the lane geometry and signal controls. Protected and permitted turns are considered correctly. In ICA method according to Highway Capacity Manual (HCM) 2010, volume-delay functions are usually used to model the volume-dependent travel times for turns or complete nodes (National Research Council (U.S.) Transportation Research Board, 2010). Fig. 8 shows the comparison between turn times of base volume with the actual volume at each intersection based on the volume-delay functions which show that the turn times at each node of actual survey data is quite large even more than $70 \%$ than the base version which represents that the traffic volume in base PTV Visum file is very less than the real-time situation during morning peak hours. The turn time differences are compared statistically by the Wilcoxon Signed Rank test, by considering normal distribution, the $\mathrm{z}$ value calculated is 2.03 and by considering $5 \%$ significance level corresponding $\mathrm{z}_{\text {critical }}$ value is 1.96 . By assuming null hypothesis, $\mathrm{z}$ value should be between -1.96 and 1.96 , while the resultant value is 2.03 which is not between the range. Hence, the null hypothesis is rejected, from which it is quite clear that the EFM Model is significantly different from the real-time data.

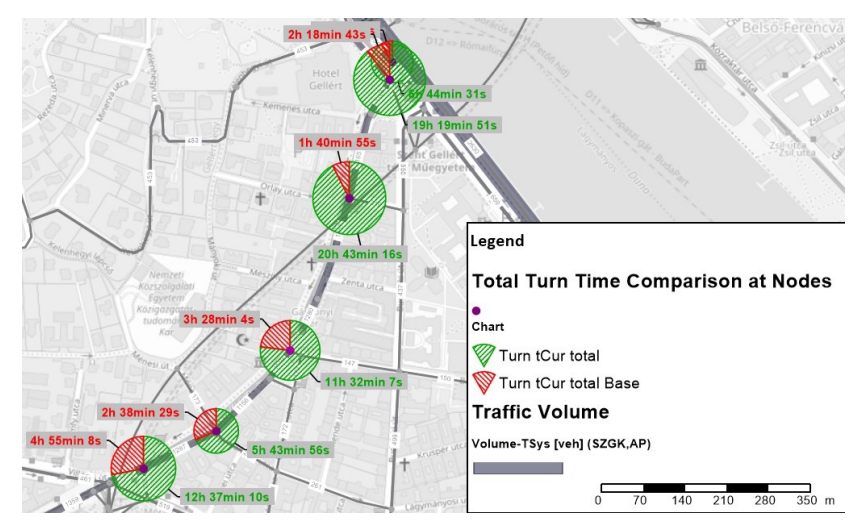

Fig. 8 Total turn travel time comparison at nodes

\subsection{Traffic volume comparison}

Traffic volumes on links after generating subnetwork for morning peak hours are compared with subnetwork of base scenario for passenger cars. The results obtained by subtracting actual traffic volume with base traffic volume which is clearly shown in Fig. 9. From the results, it is obvious that traffic volumes in base network are just assumed values which are significantly less than the actual traffic volume in the morning peak hours. In Fig. 9 there is only one link with less passenger car volume in actual volume data. In the light of these comparison results, it is obvious that the traffic volumes in the base network are just assumed values which are not representing the real-life situation.

\section{Conclusions}

The selected intersections are modelled in detail; in a way that the geometry and signal control have been edited correctly for each intersection to get the precise values of impedances, and capacities at turns and intersection levels by the PrT assignment with ICA. However, the procedure required more computations than the standard equilibrium assignment, since it determines the parameters after many iterations, therefore this assignment is more appropriate for delays calculations at turns level. From the calculated saturated time headways of surveyed traffic data, it is concluded that EFM model was designed on some user-defined fixed saturation flow rate. Furthermore, delays are calculated at node levels to execute the LOS for each intersection, which concludes that all selected intersections are operating efficiently except northbound leg of Szent Gellert ter Muegyetem intersection and southbound leg of Csiky ut - Orlay ut intersection which experienced congestion for some time during traffic counts survey.

The uniqueness of ICA assignment is that it uses volume-delay functions at nodes, which increases with increases in volumes. In a network model, turn and node volume-delays functions have more importance compared to the links because they have a more significant

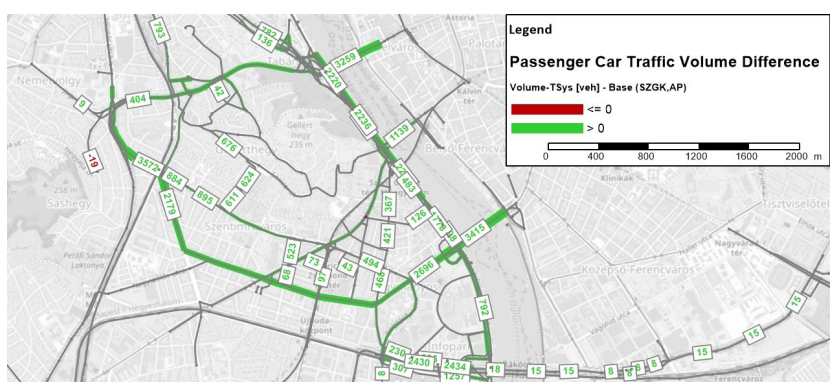

Fig. 9 Traffic volume difference of passenger car 
influence on the network performance than the delays on the links. As the comparisons are done for travel times on zones, links, nodes and turns level in PTV Visum, besides the statistical analysis on the comparison results, it is evidenced that the base EFM model is significantly different from the actual simulated model.

\section{Recommendations}

In this research, only five intersections are selected in Budapest city for the analysis by random sample size technique, in which there is always uncertainty if the sample is randomly chosen. Therefore, for further future research, it is recommended that, to choose an appropriate sample size technique. This research can be extended on city level to simulate the whole city model precisely, but for those huge resources will be required for the traffic counts surveys

\section{References}

Carter, M., Rakha, H., Aerde, M. V. (1999) "Variability of traffic-flow measures across freeway lanes", Canadian Journal of Civil Engineering, 26(3), pp. 270-281.

https://doi.org/10.1139/cjce-26-3-270

Chubukov, A., Kapitanov, V., Monina, O., Silyanov, V., Brannolte, U. (2017) "Calculation of Traffic Capacity of Signaled Intersections", Transportation Research Procedia, 20, pp. 125-131. https://doi.org/10.1016/j.trpro.2017.01.032

Daganzo, C. F., Geroliminis, N. (2008) "An analytical approximation for the macroscopic fundamental diagram of urban traffic", Transportation Research Part B: Methodological, 42(9), pp. $771-781$.

https://doi.org/10.1016/j.trb.2008.06.008

National Research Council (U.S.). Transportation Research Board (2010) "Highway Capacity Manual 2010 (HCM2010)", Transportation Research Board, Washington, DC, USA.

Shao, C., Rong, J., Liu, X. (2011) "Study on the Saturation Flow Rate and Its Influence Factors at Signalized Intersections in China", Procedia - Social and Behavioral Sciences, 16, pp. 504-514. https://doi.org/10.1016/j.sbspro.2011.04.471 along with correct geometries and control system of all intersections.

Based on the results obtained from this research, it is highly recommended to update the EFM Model because there is a significant difference between standard coding and more detailed junction coding in databases. Consequently, it is very important to have detail junction coding in Budapest Transport Model. If we would not do that then we are not aware of real-life situations.

\section{Acknowledgement}

Author of this research would like to say thanks to Dr. Tibor Sipos for his support during whole research period and managing director, Bence Verebelyi of relativeGAP Ltd. Company, who shared their knowledge and support to the authors.

Smeed, R. J. (1968) "Traffic Studies and Urban Congestion", Journal of Transport Economics and Policy, 2(1), pp. 33-70.

Szabó, Z., Török, Á., Sipos, T. (2019) "Order of the Cities: Usage as a Transportation Economic Parameter", Periodica Polytechnica Transportation Engineering, 49(2), pp. 164-169. https://doi.org/10.3311/PPtr.13786

Szabó, Z., Török, Á. (2019) "Spatial Econometrics - Usage in Transportation Sciences: A Review Article", Periodica Polytechnica Transportation Engineering, 48(2), pp. 143-149. https://doi.org/10.3311/PPtr.12047

Tang, K., Nakamura, H. (2008) "Impacts of Group-based Signal Control Policy on Driver Behavior and Intersection Safety", IATSS Research, 32(2), pp. 81-94. https://doi.org/10.1016/S0386-1112(14)60211-9

Tian, Z. (2002) "Capacity Analysis of Traffic-Actuated Intersections", MSc Thesis, Massachusetts Institute of Technology.

US Department of Transportation Federal Highway Administration (2004) "LTPP: Year in Review: 2003", U.S. Department of Transportation, Washington, DC, USA, Rep. FHWA-HRT-04-041. 